University of South Florida

DIGITAL COMMONS

Digital Commons @ University of

@ UNIVERSITY OF SOUTH FLORIDA

South Florida

$11-16-2009$

\title{
Increasing Independence Among Children Diagnosed With Autism Using a Brief Embedded Teaching Strategy
}

Stephanie Toelken

University of South Florida

Follow this and additional works at: https://digitalcommons.usf.edu/etd

Part of the American Studies Commons

\section{Scholar Commons Citation}

Toelken, Stephanie, "Increasing Independence Among Children Diagnosed With Autism Using a Brief Embedded Teaching Strategy" (2009). USF Tampa Graduate Theses and Dissertations.

https://digitalcommons.usf.edu/etd/51

This Thesis is brought to you for free and open access by the USF Graduate Theses and Dissertations at Digital Commons @ University of South Florida. It has been accepted for inclusion in USF Tampa Graduate Theses and Dissertations by an authorized administrator of Digital Commons @ University of South Florida. For more information, please contact digitalcommons@usf.edu. 


\title{
Increasing Independence Among Children Diagnosed With Autism Using a Brief Embedded Teaching Strategy
}

by

Stephanie Toelken

\begin{abstract}
A thesis submitted in partial fulfillment of the requirements for the degree of Master of Arts Department of Child and Family Studies College of Behavioral and Community Sciences University of South Florida
\end{abstract}

Major Professor: Raymond G. Miltenberger, Ph.D.

Timothy Weil, Ph. D.;

Kwang-Sun Blair, Ph. D.

Date of Approval

November 16, 2009

Keywords: training, inclusion, prompting, staff, training

(C) Copyright 2009, Stephanie Toelken 


\section{Table of Contents}

List of Figures

Abstract iii

$\begin{array}{ll}\text { Introduction } & 1\end{array}$

$\begin{array}{lr}\text { Method } & 6\end{array}$

$\begin{array}{ll}\text { Participants and Setting } & 6\end{array}$

$\begin{array}{ll}\text { Target Behaviors } & 7\end{array}$

$\begin{array}{lr}\text { Observation and IOA } & 8\end{array}$

$\begin{array}{ll}\text { Experimental Design } & 9\end{array}$

$\begin{array}{ll}\text { Results } & 12\end{array}$

$\begin{array}{ll}\text { Discussion } & 16\end{array}$

$\begin{array}{ll}\text { References Cited } & 22\end{array}$

Appendices $\quad 24$

Appendix A: Written Training Manual 25 
List of Figures

Figure 1. Student 1 Independence Level

Figure 2. Student 2 Independence Level 
Increasing Independence among Children Diagnosed with Autism Using a Brief

\author{
Embedded Teaching Strategy \\ Stephanie Toelken
}

\begin{abstract}
The purpose of this study was to evaluate the effects of a brief embedded teaching procedure, involving least-to-most prompting, for two paraprofessional staff in order to increase independent responses of two children diagnosed with autism in an inclusive setting. Training was given using a behavioral skills training approach, involving instructions, modeling, rehearsal, and feedback. The staff were trained to use the SWAT procedure used by Parsons, Reid and Lattimore (2009). A multiple baseline design across behaviors was used to evaluate the effects of the embedded teaching procedure. Maintenance of training effects was evaluated two weeks following the end of the study. After training of the brief embedded prompting procedure and during the following up probes, both students showed increased independence in each skill that staff were trained to teach.
\end{abstract}




\section{Introduction}

Because of their learning needs and behavioral difficulties, children with disabilities often have a teacher or staff working with them in a variety of capacities. To work effectively with children with disabilities requires specific training in teaching strategies and strategies for managing behavioral difficulties. A variety of studies have shown that teachers, paraprofessionals, supervisors, and others have been successfully trained to work with children diagnosed with disabilities. Over time, these studies on the effectiveness of behavioral strategies for teaching support staff to work with children with disabilities have been conducted in different settings such as group homes (Green, Rollyson \& Pasante, 2002), special education classrooms (Jensen, Parsons \& Reid, 1998), and inclusive settings (Schepis, Ownbey \& Parsons, 2000; Schepis, Reid, Ownbey \& Parsons, 2001).

Recently, the popularity of non-inclusive settings for children with autism has shifted toward an interest in more inclusive settings that include children diagnosed with disabilities in classrooms and afterschool programs provided to typically developing children. Accordingly, the popularity of inclusive settings has created a need for ways to teach children diagnosed with autism in the natural educational environment alongside typical peers. One such strategy is embedded teaching, a naturalistic approach in which children are taught during typically occurring routines. During embedded teaching the classroom environment is set up so that skill training occurs 
during tasks that are interspersed or embedded into the day's naturally occurring activities (McDonnell, 1998). For example, if the child needed to learn the preposition "in," the teacher might make sure that child's straw was not in his juice when he sat down for snack time. Snack time would be a naturally occurring activity during which the teacher could teach the preposition "in." Bricker (1995) refers to naturalistic teaching when promoting her case for inclusion of children with autism by stating the need for "activity-based approaches." Activity-based approaches are training opportunities that are also embedded into naturally occurring routines. By using activity-based approaches or embedded teaching, teachers can alter the activity based on the developmental level of the child, creating a better learning environment for the student.

Naturalistic approaches such as embedded teaching or activity-based instruction have been used to teach a variety of skills. For example Fox and Hanline (1993) taught play skills to a 4-year-old with Down's syndrome and a 4-year-old with mild developmental delays in two separate inclusive settings and showed that the results generalized to a different therapist and to an additional setting. Losardo and Bricker (1994) compared an activitybased approach with a direct-instruction approach to teach children how to label objects. Results showed that children labeled more objects that were taught during the activity-based approach than objects that were taught during the direct-instruction approach. Embedded teaching also has been used to teach target skills to children during transitions between activities (Wolery, Anthony, \& Heckathorn, 1998). 
Many staff working with children with disabilities do not have the skills needed to do their job effectively because they have not been properly trained to use procedures that have a substantial impact on these children (Graziano \& Kratz, 1982; Harchick, Sherman, Hopkins, Strouse \& Sheldon, 1989). Professionals have used many techniques to train and maintain the behaviors identified as beneficial to children with disabilities. A commonly used technique is behavioral skills training procedures (i. e., instructions, modeling, rehearsal, and/or feedback) employed to teach staff to implement discrete-trail teaching procedures (Dib \& Sturmey, 2007), to use behavior modification procedures such as providing clear discriminative stimuli, prompting, shaping, and consequences correctly in a classroom (Koegel, Russo, \& Rincover, 1977) and to conduct paired stimulus preference assessments (Lavie \& Sturmey, 2002). Workshops and classroom trainings including procedures such as observation, feedback, and instructions, have also been used to teach staff to implement token economies (Harchick, Sherman, \& Sheldon, 1992) and to aid supervisors in giving feedback to their staff (Parsons, Reid, \& Green, 1993).

Within the research on teaching staff to implement effective teaching procedures, the behaviors identified as beneficial vary across studies and environments. For example, Dib and Sturmey (2007) taught teachers how to use discrete-trial teaching methods in the classroom to reduce students' stereotypical behaviors. Discrete-trial teaching methods were also taught via instructions and feedback to paraprofessional staff working one-on-one in a child's home to aid with the acquisition of new skills by the child (Sarokoff \& 
Sturmey, 2004). Parsons and Reid (1995) used instructions and feedback to teach residential home supervisors how to give feedback to maintain staff behavior. In addition, Schepis and colleagues (2001) found that the use of behavioral skills training procedures including instructions, role-play, and feedback improved paraprofessionals' use of embedded teaching techniques in an inclusive preschool classroom which resulted in an increase in independent skills by five children diagnosed with disabilities. During the classroom training, written and verbal instructions along with explanations of why the target behaviors were important were given to the participants. After instructions were given, researchers and participants engaged in roleplays where the researchers acted out the target behaviors of the staff member and the students while participants observed. The participants then engaged in a role-play in which they acted as the staff member and the researcher acted as the child. Following the role-play section of training, participants were given on-the-job training. Next, the researchers provided feedback to participants to maintain their performance of the embedded teaching skills in the natural environment. The target behaviors that Schepis et al. (2001) measured were correct prompting, correct error correction, and correct reinforcement by staff. A teaching opportunity was scored as correct only if all of the target behaviors were performed correctly. Responses made by students were scored as an independent response, a prompted response, or no response.

In a recent study by Parsons, Reid \& Lattimore (2009) staff were trained to implement a procedure involving least-to-most prompting and 
praise in order to increase independence among adults with severe autism in a community setting. Parsons et al. called the procedure SWAT; an acronym for "Say, Wait, and watch, Act out, Touch to Guide." The purpose of the acronym, SWAT, was to help the staff remember the sequence of steps they needed to engage in to help their clients achieve independence during tasks. The results of this study showed that the brief, efficient training procedure was sufficient to promote staff use of the prompt fading procedures to promote more independence in the clients during daily activities.

The brief training procedure demonstrated to be effective by Parsons et. al. (2009) holds promise for promoting independence among children and adults with a variety of disabilities including autism. However, more research needs to be done to establish the generality of this brief training procedure evaluated by Parsons and colleagues. The purpose of this project was to provide a systematic replication of Parsons et al. by examining the effects of a brief embedded teaching procedure. In contrast to the staff working with adults with disabilities in a supported work environment who participated in the study by Parsons et al., the participants in this study consisted of teachers of children diagnosed with autism in an inclusive preschool setting. 
Method

Participants and Setting

The participants of this study included 2 paraprofessional staff, each working one-on-one with a child diagnosed with autism in an inclusive classroom setting. The staff participants were 22 years of age and 25 years of age and both held a bachelor's degree in psychology. During her involvement with the study Staff 1 was completing online coursework to obtain her BCaBA (Board Certified assistant Behavior Analyst). She had been working at the school for 8 months prior to the beginning of the study. Staff 2 had recently completed her bachelor's degree and had been working at the school for 4 months prior to the start of this study. Both staff members had previously participated in trainings held by the school. These trainings include a training on discrete-trial training and a training on general verbal behavior. Child number 1 was a 5 year-old boy diagnosed with autism. Child 1 could perform simple tracing skills, follow simple directions (i.e. "come here," "sit down," "stand up," etc.), count to 10, and mand for preferred items as well as objects needed for a task. Child number 2 was a 4 year-old boy diagnosed with autism. Child 2 was non-verbal; however he exhibited approximately four to six signs per day to request preferred items. His gross motor and fine motor skills were limited; for example he could not climb ladders, run smoothly or complete fine motor skills such as tracing, puzzles, and stacking blocks. The study was conducted during lunch time 
hours (Child 1) and during the time the children packed to go home (Child 2) in the regular classroom at a private school for children with and without autism in west central Florida.

Target Behaviors

The target behaviors consisted of the level of prompting delivered by staff and the students' behaviors in completing a task.

Student behaviors. Target behaviors for each child were selected via direct observation by the primary researcher and based on tasks that the one-on-one staff completed for the child that the child could learn to complete independently. Three tasks were selected for each child. Tasks for child 1 consisted of rubbing his hands together while washing, opening his lunch box, and wiping the table after lunch. Tasks for child 2 consisted of putting papers into his backpack, putting on his backpack, and opening the door when leaving the classroom. Behavior definitions for child 1 were as follows: Rubbing his hands while washing was defined as putting his hands together under running water and moving them back and forth at least 2 times. Opening his lunch box consisted of removing the latch and opening the box completely. Wiping the table was defined as taking a wet wipe from the container and wiping the area where he ate lunch (approximately 1 square foot). Behavior definitions for child 2 were as follows: Putting papers in his backpack was defined as taking all of the papers that were in the child's cubby out and placing them in his backpack (papers could be placed in his backpack in any manner). Putting on his backpack consisted of taking his backpack off the hook and putting it on his back facing the right direction 
with his arms through the straps. Opening the door was defined as using any method to move the door from a closed position to an open position.

Staff behaviors. Data were collected according to prompt level of the staff member and independence level of the student in the same manner Parsons, Reid \& Lattimore (2009) collected data. A "0" was recorded if staff completed the behavior for the child and there was no independent behavior exhibited by the child. A "1" was recorded if staff used full physical guidance to guide the child through the task. A " 2 " was recorded if partial physical guidance was used by the staff member, which meant the child completed some of the task with physical guidance and some of the task wih gestural prompts or independence. A "3" was recorded if the staff member used gestures to prompt the child and the child did not require any physical guidance. A "4" was recorded if the staff member did not prompt the child and the child completed the task independently in response to the $S^{D}$ (a verbal request to complete the task).

\section{Observation and Interobserver Agreement}

Probe data were collected by the primary researcher. For child 1 , the activity consisted of a lunch time routine in which he was expected to wash his hands, open his lunch box, and wipe the table after eating. For child 2, the activity was the end of the day routine and involved putting his papers in his backpack, putting on his backpack, and opening the door to exit the classroom. These behaviors were chosen for these students because staff frequently completed the behaviors for them and they were behaviors the 
children could learn in an attempt to become more independent in daily activities at school.

Interobserver agreement (IOA) checks were conducted during $38 \%$ of all observations for child 1 and $37 \%$ of all session for child 2 . IOA data were taken by another staff member at the school. The percentage of agreement was calculated on a trial by trial basis using the formula of number of agreements on the level of prompting divided by number of agreements plus disagreements and multiplied by $100 \%$. The overall agreement for child 1 was $85 \%$ and the overall agreement for child 2 was $91 \%$.

Experimental Design

A multiple-baseline design across behaviors was used to evaluate the effectiveness of the brief embedded teaching procedure for each participant. Experimental Conditions

Baseline. Baseline observations occurred during the appropriate times for each task. Data for child 1 were recorded at lunch time and data for child 2 were recorded at the end of the day when the child would normally have to put his papers in his backpack. Staff members were not told they were being observed and the classroom schedule or physical environment was not altered in any way.

Training. Training took place before school started and took approximately 10 minutes each time. One training session took place each time the procedures were applied to a new behavior. Training consisted of a written manual (see Appendix A) describing a modified SWAT support model described in Parsons et al. (2009). SWAT is an acronym for "Say," "Wait and 
watch," "Act out," and "Touch to Guide." This acronym was used to help the staff remember to use least-to-most prompting when the children did not complete the task. "Say" involved the therapist presenting the task or the demand (i.e., "Put your papers in your backpack"). "Wait and Watch" consisted of the therapist waiting 3-5 seconds for the child to initiate or complete the task. "Act Out" occurred if the child did not initiate or complete the task and involved a gestural prompt (i.e. pointing to the backpack) and repeating the "Wait and Watch" procedure (i.e. waiting 3-5 seconds for the child to initiate or complete the task). "Touch to guide" occurred when the child did not initiate or complete the task and involved the use of a partial physical prompt in which the therapist gently guided the child to perform the activity (i.e. gently push the elbows toward the backpack). If the child did not complete the task within 3 seconds after the partial physical prompt was given, the therapist provided full physical prompting for the child to complete the task. After the entire SWAT procedure was trained, the staff were then trained to use behavior specific praise simultaneously with touch and/or tickles. Their teachers identified behavior specific praise, touch, and tickles as reinforcers for both of the children. Next, the primary researcher modeled the procedure using the staff member as the child. Additionally, the staff member rehearsed the procedure with the primary researcher acting as the child. Finally, feedback was given to the staff; praise was given for correct prompting, waiting, and reinforcement and corrective feedback was given if mistakes were made. If mistakes were made the staff member rehearsed the task until the entire process was done correctly. Although training took 
place in the morning before school once for each target behavior, no feedback or other consequences were delivered for the correct or incorrect use of the procedures with the student during the regular daily routine during which data were collected.

Follow-up. Follow up probes were conducted two weeks and four weeks after completion of the final intervention probe. Follow-up probes were collected in the same manner as post-training probe data was collected. 
Results

During baseline, staff completed each task for both children. After training was implemented, child 1 and child 2 both completed all three tasks with more independence and, in most cases completely independently, after approximately ten sessions.

Child 1 exhibited improvement immediately after training was provided for staff. Opening lunch box was the first target behavior on which intervention focused. Immediately during intervention the child performed this task with only partial physical assistance from the therapist. Additionally, during the second and third observation after training, the staff member used a gestural prompt. By the fourth session, he was engaging in the behavior independently. Child 1 also increased his level of independence after training was implemented on the wiping table task and the rubbing hands task. Although, the child did perform these tasks independently, he still required a gestural prompt at times. Child 1 became completely independent with 1 of the 3 tasks on which the staff was trained.

During follow-up observations child 1 maintained his independence with each task on which the staff was trained. In addition, in one case (rubbing hands task) the child became more independent during the followup observations. 


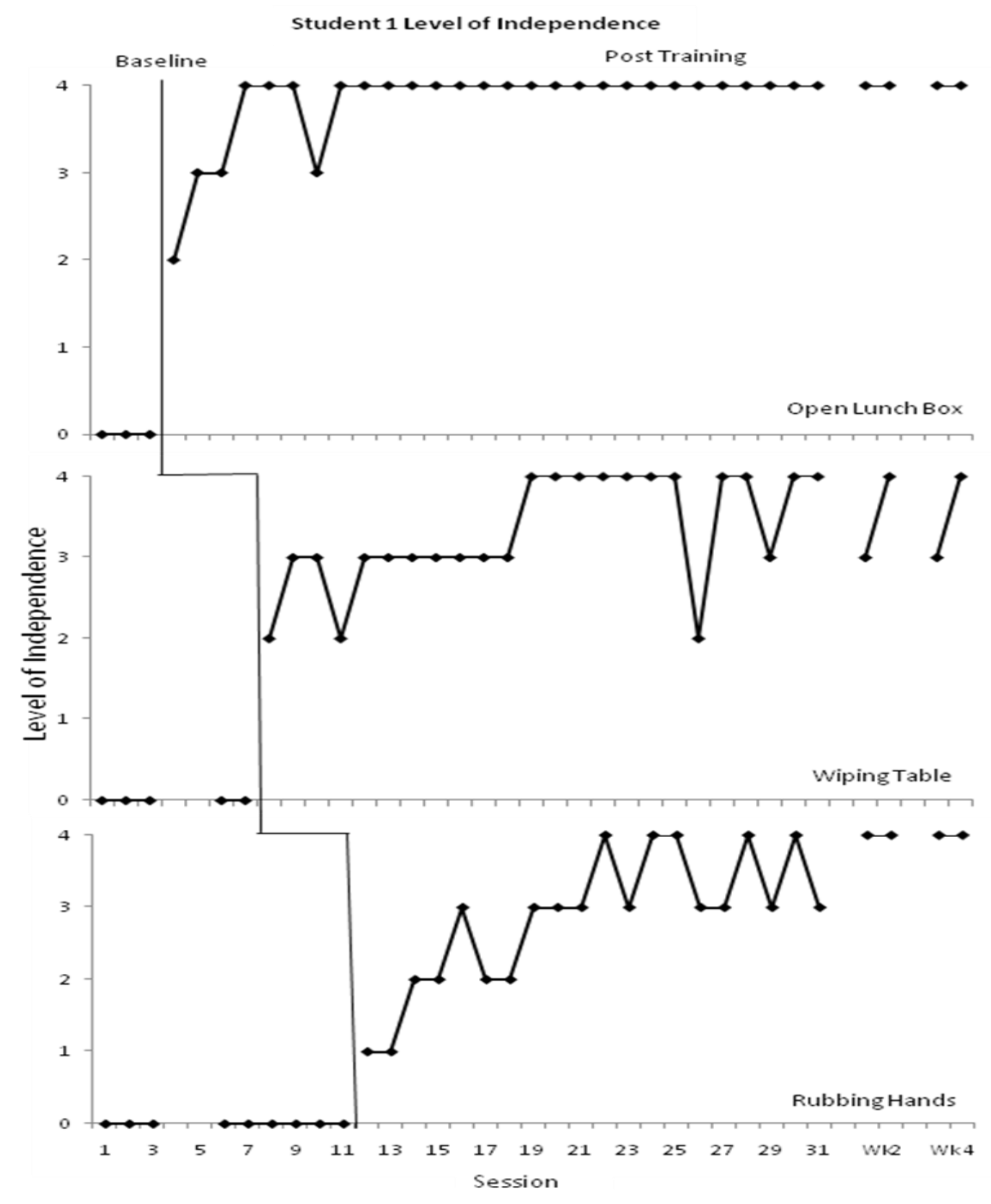

Figure 1. Level of independence demonstrated by Student 1 during baseline and after training was conducted. Level of independence is represented on the Y-axis by " 0 " (Staff completed the task for the student), "1" (A full physical prompt was used), "2" (a partial physical prompt was used), " 3 " (a gestural prompt was used) and " 4 " (the child completed the task independentlv). 
Results for child 2 were similar to the results for child 1 . During baseline the therapist completed each task for the child. Immediately after training was implemented for the task that required the child to put his papers in his backpack the therapist used a full physical prompt. During the second observation during intervention for this task the child required only a gestural prompt. During the seventh session after training the child performed the task independently, however, gestural prompts were used during the next three observations. The child did begin to perform the task independently for several sessions; however, gestural prompts were still sometimes needed for the child to complete this task.

Child 2 also became more independent after training was implemented for staff on the tasks putting on backpack and opening door. By the fourteenth session in the intervention phase he was putting on his backpack with only a gestural prompt. By the seventh session of intervention he was opening the door independently. These results show that Child 2 became completely independent with opening the door and mostly independent with putting papers in back pack. For the third behavior, his level of independence rose to just needing a gestural prompt.

During follow-up observations child 2 maintained the same level of independence as seem in the intervention phase with each task on which the staff was trained. 


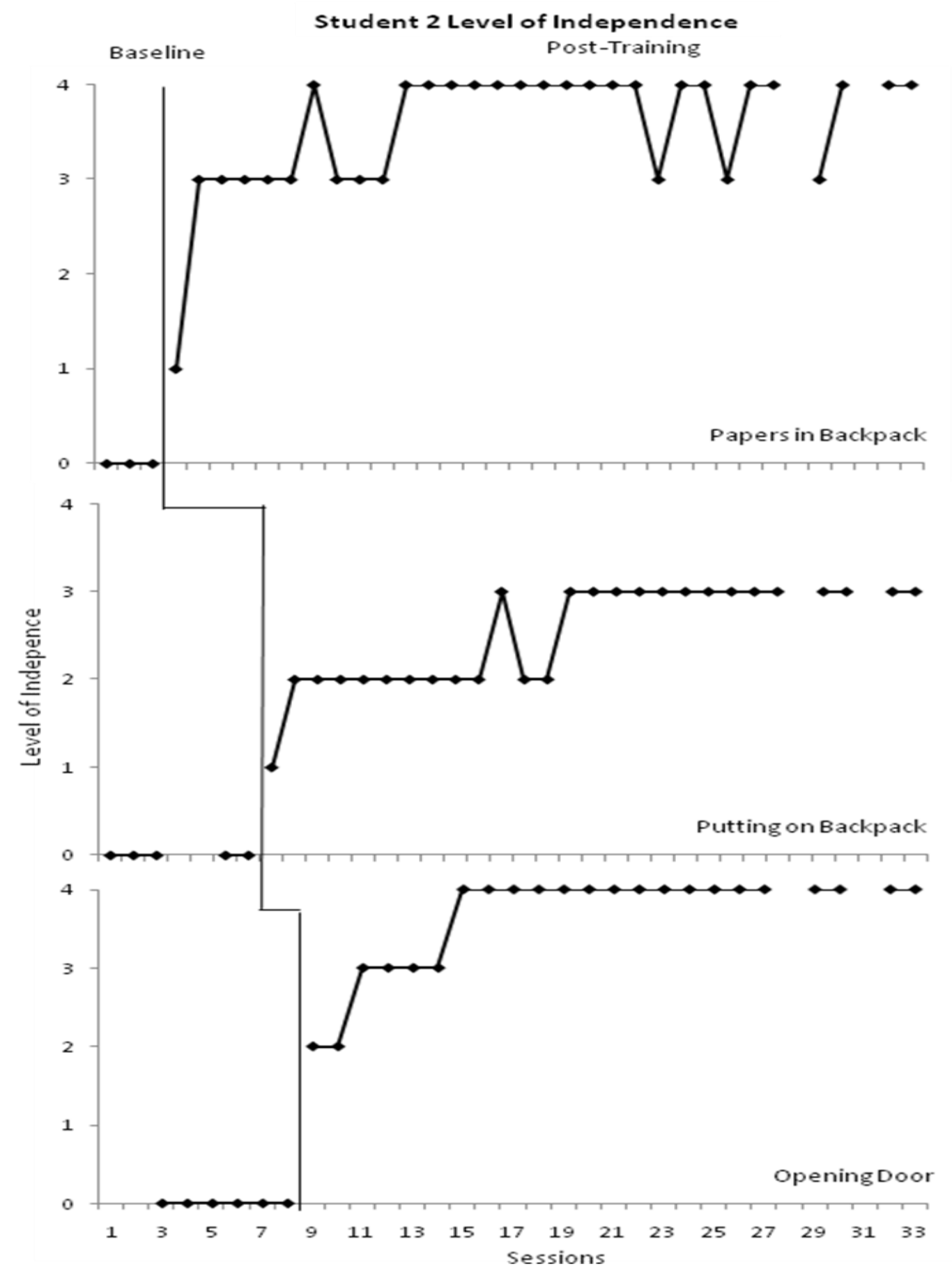

Figure 2. Level of independence demonstrated by Student 2 and prompt used by staff during baseline and after training was conducted. Level of independence is represented on the Y-axis by " 0 " (Staff completed the task for the student), "1" (A full physical prompt was used), "2" (a partial physical prompt was used), "3" (a gestural prompt was used) and " 4 " (the child completed the task independently). 
Discussion

These results support the findings from Parsons et al. (2009) and further extend the research of using the SWAT model to train staff that work with children diagnosed with autism in an inclusive classroom setting. Both children showed increased independence across all tasks as staff stopped completing the tasks for them and started prompting and fading procedures to get the children to complete the tasks as independently as possible. As a result of their staff participating in the training, these two children now engaged in behaviors they were fully capable of performing but previously failed to perform because staff completed the behaviors for them. Each time the training was applied to a new behavior, the independent execution of that behavior increased with no corresponding decrease in independence of the previously targeted behaviors. Based on these findings, it may be possible to apply these procedures successfully with numerous other behaviors that should be (but are not currently being) performed independently by the children across the school day and at home.

One benefit of the training procedures used in this study is that they were brief, taking approximately 10 minutes for each task that was taught. The efficiency of the training procedures is important because agencies are more likely to implement training and staff are more likely to participate in training if it does not take substantial time away from their duties on the job. Furthermore, the staff involved in this study were excited to participate in 
the trainings for the $2^{\text {nd }}$ and $3^{\text {rd }}$ target behaviors, perhaps due to the short time it took for the training and the success that occurred with the children after the training.

Another benefit of the training procedures was the use of the acronym, SWAT. By associating the training activities expected of staff with this simple acronym, it is possible that they were more likely to use the procedure successfully with the students. Although the study did not test the effectiveness of the use of the acronym versus similar training without the use of the acronym, the acronym may have provided a pneumonic device that cued staff to perform the behaviors correctly. If the use of the acronym did increase the likelihood that staff would use the procedures, it may have produced this effect through a process of rule governed behavior (Malott \& Suarez, 2004). More research needs to be conducted to see if the use of the acronym influenced staff behavior in this way.

Although these results are positive in demonstrating the effectiveness of the SWAT procedure for promoting independence, there were some limitations that should be noted. First, there may have been some reactivity to observations from the primary researcher who was also the trainer. Although, the primary researcher sat in the corner of the room, she was still visible to staff. However, the researcher was a teacher in the school who was present most days, and not just on observation days. Therefore, because her presence was not uniquely associated with the study it may not have influenced the participants' behavior much if at all. Furthermore, the researcher never commented or provided any sort of feedback on the staff or 
child's behavior during an observation. This fact also may have limited the reactivity that may have resulted from the researcher's presence. Unfortunately, because the study did not specifically test for reactivity of observation, the effects of reactivity, if any, are unknown. More research needs to be conducted to evaluate the influence of reactivity on staff performance in staff management investigations (e.g., Brackett, Reid, \& Green, 2007; Mowery, Miltenberger, \& Weil, in press).

Secondly, the SWAT model consisted of the "Say" step in which a verbal $S^{D}$ was always presented in the situation where the behavior was to occur. Therefore, data were always based on the staff giving an $\mathrm{S}^{\mathrm{D}}$. It is not clear whether the children would have executed the behaviors in the absence of a verbal $S^{D}$ because we did not assess the behaviors without the $S^{D}$. Interestingly, Child 1 did engage in opening his lunch box before the $S^{D}$ was given by the staff member on several occasions, and on one occasion Child 2 engaged in opening the door before there was an $S^{D}$ presented. A more systematic evaluation of the behavior in the absence of the verbal request would have been valuable to determine whether the appropriate context for the behavior developed stimulus control over the behavior.

Also, we did not measure the difficulty of each task for the children (i.e., how many steps were involved with each task, previous mastery of similar tasks). Difficulty of the tasks may have resulted in differences in the level of independence the child exhibited. For example, opening a lunch box may be an easier task for Student 1 than wiping the table and rubbing hands, which may be why he reached complete independence with the 
opening lunch box task but not the others. Similarly, child 2, reached independence with opening the door, whereas prompting was variable during the papers in backpack task. Child 2 also reached independence in fewer sessions with the opening door task than with the putting papers in backpack task. Future research should evaluate task difficulty as a variable that might influence the effectiveness of the SWAT procedure.

Furthermore, treatment fidelity data were not collected. Therefore, it is not know whether the staff implemented the prompting procedure correctly. The data suggest that the prompting was done correctly due to the incremental changes from session to session. However, some data are variable and it is not known whether staff may have missed a prompt in the hierarchy, prompted too quickly or implemented a higher level of prompting when a lesser amount would have been sufficient.

Lastly, we do not know if the skills the staff obtained during training or the skills the children were performing independently generalized across other tasks, environments, or therapists. It may have been beneficial to observe the staff working with other behaviors of the same target children to better determine if staff used the skills with other target behaviors without specific training. In addition to an assessment of generalization of the skills across behaviors of the same children, it also would be valuable to observe the staff with other children to see if the training generalized across other children as well. Finally, it would be valuable to observe the target children with other staff to see if the children completed the three skills with the same 
level of independence when other staff were present. Future research should evaluate these generalization questions.

In summary, the findings of this study proved to be consistent with the findings of Parsons et al. (2009). Using the SWAT acronym along with a behavioral skills training approach was an effective strategy for training paraprofessional staff to use least-to-most prompting. Furthermore, the short training procedure was effective in developing independence with skills performed by children diagnosed with autism 


\section{References Cited}

Brackett, L., Reid, D.H., \& Green, C.W. (2007). Effects of reactivity to observations on staff performance. Journal of Applied Behavior Analysis, 40(1), 191-195.

Bricker, D. (1995). The challenge of inclusion. Journal of Early Intervention, $19,179-194$

Dib, N., \& Sturmey, P. (2007). Reducing student stereotpy by improving teachers " implementation of discrete-trail-teaching. Journal of Applied Behavior Analysis, 40, 339-343.

Fox, L. \& Hanline, M. (1993). A preliminary evaluation of learning within developmentally appropriate early childhood settings. Topics in Early Childhood Special Education, 13, 308-327.

Graziano, A. M., \& Krantz, J. N. (1982). Training paraprofessionals. In A. S. Bellack, M. Hersen, \& A. E. Kazdin (Eds.) International handbook of behavior modification and therapy (pp. 207-229). New York: Plenum.

Green, C. W., Rollyson, J. H., \& Passante, S. C. (2002). Maintaining proficient supervisor performance with direct support personnel: an analysis of two management approaches. Journal of Applied Behavior Analysis, 35, 205-208.

Harchick, A. E., Sherman, J. A., Hopkins, B. L., Strouse, M. C. \& Sheldon, J. B. (1989). Use of behavioral techniques by paraprofessional staff: a review and proposal. Behavioral Residential Treatment, 4, No. 4.

Harchik A. E., Sherman, J. A., Sheldon, J. B., \& Strouse, M. C. (1992). Ongoing consultation as a method of improving performance of staff members in a group home. Journal of Applied Behavior Analysis, 25, 599-610.

Jensen, J. M., Parsons, M. B., Reid, D. H. (1998). Supervisory training for teachers: multiple, long-term effects in an education program for adults with severe disabilities, Research in Developmental Disabilities, $19,449-463$. 
Koegel, R. L., Russo, D. C., \& Rincover, A. (1977). Assessing and training teachers in the generalized use of behavior modification with autistic children. Journal of Applied Behavior Analysis, 10, 197-205.

Lavie, T., \& Sturmey, P. (2002). Training staff to conduct a paired-stimulus preference assessment. Journal of Applied Behavior Analysis, 35, 209211.

Losardo, A., \& Bricker, D. (1994). Activity-based intervention and direct instruction: A comparison study. American Journal On Mental Retardation, 98, 744-465.

Malott, R. W., \& Suarez, E. A. (2004). Principles of behavior ( $5^{\text {th }}$ ed.). Pearson Prentice Hall. Upper Saddle River, NJ.

McDonnell, J., Johnson, J. W. (2002). Effects of embedded instruction on students with moderate disabilities enrolled in general education classes. Education And Training In Mental Retardation And Developmental Disabilities, 37, 363-377.

Mowery, J., Miltenberger, R., \& Weil, T. (in press). Evaluating the effects of reactivity to supervisor presence on staff response to tactile prompts and self-monitoring in a group home setting. Behavioral Interventions.

Parsons, M. B. \& Reid D. H. \& Green, C. W. (1993). Preparing direct service staff to teach people with severe disabilities: a comprehensive evaluation of an effective and acceptable training program. Behavioral Residential Treatment, 8, 163-185.

Parsons, M. B., Reid, D. H. \& Lattiomore, P. (2009). Increasing Independence Among Adults with Autism in Community Activities: A Brief Embedded Teaching Strategy. Behavior Analysis in Practice, 2, 40-48.

Sarokoff, R. A., \& Sturmey, P. (2004). The effects of behavioral skills training on staff implementation of discrete-trial teaching. Journal of Applied Behavior Analysis, 37, 535-538.

Schepis, M., Reid, D. H., Ownbey, J., \& Parsons, M. B. (2001). Training support staff to embed teaching within natural routines of young children with disabilities in an inclusive preschool. Journal Of Applied Behavior Analysis, 34, 313-327.

Schepis, M. M., Ownbey, J. B., Parsons, M. B., \& Reid, D. H. (2000). Training support staff for teaching young children with disabilities in an inclusive preschool setting. Journal Of Positive Behavior Interventions, 2, 170-178 
Wolery, M., Anthony, L., \& Heckathorn, J. (1998). Transition-based teaching: Effects on transitions, teacher's behavior, and children's learning. Journal of Early Iintervention, 21, 117-131. 
Appendices 
Appendix A: Written Training Manual

\section{SWAT}

SAY:

\section{WAIT \& WATCH:}

\section{ACT OUT:}

\section{TOUCH TO GUIDE:}

\section{PRAISE:}

Provide a gestural prompt!

Point or give an expectant look.

EXAMPLE:

Point to the (insert target skill here)

*wait \& watch 3-5 seconds: If child does not complete the skill, move to the next step.

\section{Provide a partial physical or full physical} prompt.

Start with a partial physical prompt: touch the child's arms gently and guide them through the first part of the skill.

*wait \& watch 3 seconds: If child does not complete the skill or makes a mistake... Provide a full physical prompt: Guide the child through the remainder or the entire skill.

EXAMPLE:

Place finger under child's wrist and guide child's hands to touch the latch on the lunch box (insert target skill here). Remove hands, but stay close

*If child does not complete the task...

Hold the tops of child's hands and guide them to touch the latch of the lunch box, unhook the latch and lift the lid.

Give the child Praise!

Use behavior specific statements and positive words along with touch or tickles. 